\title{
Tratamento de sarcóide equino com Euphorbia tirucalli - relato de caso
}

Tayna Rosendo, Camila Agostinho Sartori, Renan Borges Inacio, Arnaldo Sotero Luz Souza, Fernanda Tamara Neme Mobaid Agudo Romão

Faculdade de Ensino Superior e Formação Integral (FAEF), Luiziânia, SP, Brasil

*Autor correspondente

e-mail: ftnmaromao@gmail.com

\section{Resumo}

O sarcoide equino é a neoplasia cutânea com maior frequência em equinos, não tendo predileção por raça, sexo, pelagem ou idade. A etiologia ainda não é completamente definida, e a associação do papiloma vírus bovino (PVB-1 e PVB-2) parece ser um fator predisponente para o sarcóide. As lesões são mais comuns na face, membros e abdômen ventral. As lesões podem ser classificadas através de sua aparência macroscópica, podendo ser fibroblástica, papilomatosa, nodular, mista ou oculta. 0 diagnóstico pode ser clínico, tendo sua confirmação através de biópsia; já o tratamento é complicado devido às recidivas frequentes. Os tratamentos que usualmente são empregados são as imunoterapias (como a hemoterapia e vacinas autógenas), uso tópico de antiviral (como o aciclovir), quimioterápicos (como imiquimode) ou, quando possível e se a região apresentar margem cirúrgica, a ressecção com sessões de criocirurgia para remoção da neoformação. 0 presente trabalho tem por objetivo relatar um caso de sarcoide equino, juntamente com a terapêutica de sucesso com o uso da planta Euphorbia tirucalli. Foi atendido no Hospital Veterinário de Grandes Animais da Faculdade de Ensino Superior e Formação Integral- FAEF um equino fêmea, da raça Quarto de Milha, com 9 anos de idade, pelagem alazã, pesando $450 \mathrm{~kg}$. 0 animal era mantido a pasto juntamente com bovinos. Segundo o proprietário, aproximadamente 6 meses antes da entrada ao HV, o animal começou a apresentar lesões na pele, principalmente na região inguinal, que não regrediam. Na chegada ao HV, após exame clínico, o diagnóstico de sarcoide foi estabelecido, apresentando as seguintes características: na comissura medial do olho direito e no ramo da mandíbula sarcoide nodular, na região inguinal direita, aspecto fibroblástico com cerca de $16 \mathrm{~cm}$ de diâmetro. No tratamento, optou-se pelo uso da planta Euphorbia tirucalli (avelós), devido a custos. Foi realizada aplicação da seiva da planta diluída em água, de injeção intralesional no sarcóide da região inguinal direita, apresentando dor e edema nos três primeiros dias e necrose de grande parte da proliferação nos dias posteriores. A lesão regrediu para aproximadamente $6 \mathrm{~cm}$. Reaplicações 
foram realizadas a cada 15 dias, totalizando quatro aplicações. Em seguida, foi realizada aplicação tópica da seiva da planta diluída em mucilagem, e em aproximadamente 2 meses, apresentou total regressão da lesão. Nas outras lesões foi usada apenas a aplicação tópica da seiva da planta, tendo todas regressão moderada. Os efeitos colaterais da aplicação intralesional foram edema e dor no local da aplicação. Já a aplicação tópica teve como efeito colateral apenas leve irritação no local. Nota-se, também, que na forma fibroblástica a resposta à aplicação tópica e intralesional da planta foi melhor do que no tipo nodular. Apesar de o tratamento tópico e intralesional com a seiva da planta Euphorbia tirucalli (avelós) ser pouco descrito, e ainda não se ter doses ou formas de aplicação bem instituídas, a aplicação intralesional e tópica se mostra eficiente, de baixo custo e sem recidivas, tornando-se uma opção viável de tratamento para o sarcoide do tipo fibroblástico equino.

Palavras-chave: Avelós. Neoplasia cutânea. Papilomavirus. 